\title{
THREE-DIMENSIONAL SOLUTIONS IN MEDIA WITH SPATIAL DEPENDENCE OF NONLINEAR REFRACTIVE INDEX
}

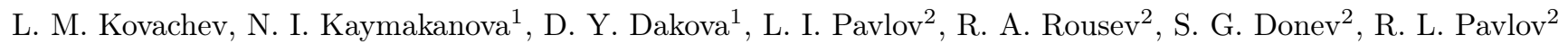 \\ Institute of Electronics, Bulgarian Academy of Sciences, \\ Tsarigradcko Chaussee 72,1784 Sofia, Bulgaria, \\ ${ }^{1}$ Plovdiv University, 24 Tsar Asen Str., 4000 Plovdiv,Bulgaria, \\ ${ }^{2}$ Institute for Nuclear Research and Nuclear Energy, \\ 72 Tsarigradsko Chaussee, 1784, Bulgaria
}

(Received January 17, 2003; received in final form June 5, 2003)

\begin{abstract}
We investigate a nonparaxial vector generalization of the scalar $3 \mathrm{D}+1$ Nonlinear Schrödinger Equation (NSE). In spherical presentation it is possible to reduce this equation to usual scalar Nonlinear Schrödinger Equation in respect to $t, r=\sqrt{x^{2}+y^{2}+z^{2}}$ coordinates. Thus, all periodical and solitary solutions of the NSE will generate $3 \mathrm{D}+1$ vector solitons. Such reduction is possible only when the spatial dependence of the nonlinear refractive index is of the type of $n_{2} \cong\left(x^{2}+\right.$ $\left.y^{2}\right) \chi^{(3)} / r_{0}$. Exact analytical $3 \mathrm{D}+1$ soliton solutions are obtained for the first time in media of spatial dependance of the nonlinear refractive index.
\end{abstract}

Key words: spatial optical solitons.

PACS number(s): 42.81.Dp, 05.45.Yv, 42.65.Tg

\section{INTRODUCTION}

The nonlinear effects in optics are of great interest in physics of the nonlinear waves. There are no difficulties now to obtain picosecond or femtosecond optical pulses with equal duration in $x, y$ and $z$ directions. The problems with so generated light bullets arise in the process of their propagation in dispersive nonlinear media. As it was established in [1-3], the scalar paraxial approximation (no dispersion in the direction of propagation), is in very good accordance with the experimental results in the transparency region of a dispersive Kerr type media. The paraxial approximation, used in the derivation of the scalar $2 \mathrm{D}+1$ nonlinear Schrödinger equation (NLS), does not include the second derivative of the amplitude function in the direction of propagation. The result in the case of a linear propagation (pulses of small intensity) is: the generated optical bullets at short distance are transformed in optical disks, with large transverse and small lengthwise dimension. Only in some special cases, as optical pulses near the Langmuir frequency or near some of the electronic resonances [4], the sign of the dispersion is negative and the scalar $2 \mathrm{D}+1$ NLS becomes $3 \mathrm{D}+1 \mathrm{NLS}$ ones [5-7]. The main result for the propagating of localized optical pulses in the dynamics of scalar $3 \mathrm{D}+1 \mathrm{NLS}$ case may be generalized as self-focusing and as instabilities of the pulses. Optical bullets under the dynamics of $3 \mathrm{D}+1$ scalar NLS are investigated also in relation to a different kind of the nonlinearity [8,9]. Generation of a new kind of 2D and 3D optical pulses, so called optical vortices, has recently become a topic of considerable interest. Generally, the optical vortices are such a type of optical pulses, which admit angular dependence of electrical field or helical phase distribution. The electrical field or intensity is zero also in the center of the vortices. The original scalar theory of optical vortices was based on the well known $2 \mathrm{D}+1$ NSE [10-12]. In a self focusing regime of propagation optical rings, can be generated but they are modulationally unstable $[13,14]$. One alternative way of stabilizing optical vortices in $2 \mathrm{D}$ and $3 \mathrm{D}$ case, using saturable $[15,16]$ or cubic- quintic $[17,18]$ nonlinearity, was also discussed. On the other hand, the experiments with optical vortices show that polarization and the vector character of the electric field play an important role in the dynamics and the stabilization of the vortices [19]. To investigate these cases we are going to a vector version of $3 \mathrm{D}+1 \mathrm{NSE}$. Solitons in the $3 \mathrm{D}+1$ Vector NLS (VNLS) case, when the nonlinear refractive index is proportional to $x^{2}+y^{2}$ are obtained in [20]. Such a profile can be obtained by doping in some new polymers [21]. The analysis of transient optical response of large organic molecules allows to estimate the nonlinear nonlocal susceptibility of such material. The spatial dependance of $\chi^{(3)}$ can be reached by diffusion effects in semiconductor technology [22] also. The oldest method for realizing such local nonlinearity variation using additional optical field was presented in [23].

In this paper, we analyze a nonparaxial vector generalization of the scalar $3 \mathrm{D}+1$ NLS with spatial dependance of nonlinear refractive index. It is important, that only in this case a reduction to usual one dimensional in $t, r=\sqrt{x^{2}+y^{2}+z^{2}}$ coordinate NLS is possible, and we obtain for the first time exact analytical soliton solutions.

\section{BASIC EQUATIONS}

The vector $3 \mathrm{D}+1$ NLS (VNLS) describing the propagation of light in a dispersive media of cubic nonlinearity and in coordinate system, which moves with group velocity $v=\partial \omega / \partial k$ is [4] :

$$
-i \frac{\partial \mathbf{A}}{\partial t}+\frac{v}{2 k_{0}} \Delta_{\perp} \mathbf{A}-\frac{v^{3} k_{0}^{\prime \prime}}{2} \frac{\partial^{2} \mathbf{A}}{\partial z^{2}}
$$




$$
+\frac{n_{2} k_{0} v}{2}|\mathbf{A}|^{2} \mathbf{A}=0
$$

where $\Delta_{\perp}=\frac{\partial^{2}}{\partial x^{2}}+\frac{\partial^{2}}{\partial y^{2}}, k$ is the carrying wave number, $k^{\prime \prime}=\partial^{2} \omega / \partial k^{2}$ is the dispersion of the group velocity and $n_{2}$ is the nonlinear refractive index. As was pointed above, we investigate the case when the nonlinear refractive index depends on the transverse coordinates $n_{2}=\left(x^{2}+y^{2}\right) \chi^{(3)} / r_{0}$. We investigate the case of negative dispersion when $k^{\prime \prime}<0$. Defining the rescaled variables:

$$
\mathbf{A}=A_{0} \mathbf{A}^{\prime} ; x=r_{0} x^{\prime} ; y=r_{0} y ; z=r_{0} z^{\prime} ; t=t_{0} t^{\prime}
$$

and constants:

$$
\alpha=k_{0} r_{0}^{2} / t_{0} v ; \beta=v^{2} k^{\prime \prime} k_{0} ; \gamma=k_{0}^{2} r_{0}^{2} n_{2}\left|A_{0}\right|^{2} / 2,
$$

equation (1) can be transformed in the following (the primes are not written):

$$
\begin{aligned}
-i \alpha \frac{\partial \mathbf{A}}{\partial t} & +\frac{1}{2} \Delta_{\perp} \mathbf{A}-\frac{1}{2} \beta \frac{\partial^{2} \mathbf{A}}{\partial z^{2}} \\
& +\gamma\left(x^{2}+y^{2}\right)|\mathbf{A}|^{2} \mathbf{A}=0
\end{aligned}
$$

The linear parameter $\beta$ in transparency region of the media is usually one or two order of magnitude smaller $\left(\beta \sim 10^{-2}\right)$. We will investigate the case, when $\beta=-1$ (negative dispersion) and $\gamma=1$. The constant $\alpha$ has a typical value of $\alpha \approx 10^{2}\left(\alpha \approx r_{0} k_{0}\right)$. Using these values, for the negative dispersion region the equation (4) becomes:

$-i \alpha \frac{\partial \mathbf{A}}{\partial t}+\frac{1}{2} \Delta_{\perp} \mathbf{A}+\frac{1}{2} \frac{\partial^{2} \mathbf{A}}{\partial z^{2}}+\left(x^{2}+y^{2}\right)|\mathbf{A}|^{2} \mathbf{A}=0$.

If the vector field satisfies the condition $\operatorname{div} \mathbf{A}=0$ equation (6) can be written as:

$-i \alpha \frac{\partial \mathbf{A}}{\partial t}-\frac{1}{2}(\nabla \times(\nabla \times \mathbf{A}))+\left(x^{2}+y^{2}\right)|\mathbf{A}|^{2} \mathbf{A}=0$.

We are solving the nonlinear vector equation (6) in spherical coordinates, $r, \theta, \varphi$ and it is convenient to write the system in a physical basis. We point here that main difficulties to solve this vector system (6) arise from the first term of the radial differential operators of the kind of:

$$
\frac{2}{r} \frac{\partial}{\partial r}+\frac{\partial^{2}}{\partial r^{2}}
$$

We try to solve the next problem: Is there such a type of vector fields, where after applying twice the vector multiplication by nabla the first (singularity) term in (7) will disappear? Then we can transform equation (6) to usual
NLS in respect to ' $r$ ' coordinate.

We find three types of vector which satisfy the conditions for the singularity term vanishing. In spherical coordinates $r, \theta, \varphi$ they are:

$$
\begin{aligned}
& \mathbf{A}=[0, B(r, t) / r \sin \theta, 0], \\
& \mathbf{A}=[0,0, B(r, t) / r \sin \theta]
\end{aligned}
$$

and their superposition:

$$
\mathbf{A}=[0, B(r, t) / r \sin \theta, B(r, t) / r \sin \theta]
$$

We should note here that these vector fields (8)-(10) satisfy also the condition $\operatorname{div} \mathbf{A}=0$. Substituting the vector fields (8)-(10) in the nonlinear vector equation (6) the next equation on $\theta$ and $\varphi$ components of the field $\mathbf{A}$ is obtained (the others are zero):

$$
-i \alpha \frac{\partial \mathbf{B}}{\partial t}+\frac{1}{2} \frac{\partial^{2} \mathbf{B}}{\partial r^{2}}+|\mathbf{B}|^{2} \mathbf{B}=0
$$

Equation (11) is one dimensional in ' $r$ ' direction NLS. Hence all solutions (periodical and solitary) of NLS, dividing dy $r \sin \theta$, generate the solutions of equation (6). In Cartesian coordinates the one-soliton solutions of (6), which are generated by the vector fields of kind of (8)(10) and NLS (11) are the following:

1. For the vector field of kind (8):

$A_{x}(x, y, z, t)=\alpha \operatorname{sech}(\alpha r) \frac{z x}{r} \frac{1}{\left(x^{2}+y^{2}\right)} \exp (-i \alpha t / 2)$,

$A_{y}(x, y, z, t)=\alpha \operatorname{sech}(\alpha r) \frac{z y}{r} \frac{1}{\left(x^{2}+y^{2}\right)} \exp (-i \alpha t / 2)$,

$A_{z}(x, y, z, t)=-\frac{\alpha \operatorname{sech}(\alpha r)}{r} \exp (-i \alpha t / 2)$.

2. For the vector field of kind (9):

$$
\begin{aligned}
& A_{x}(x, y, z, t)=-\alpha \operatorname{sech}(\alpha r) \frac{y}{\left(x^{2}+y^{2}\right)} \exp (-i \alpha t / 2) \\
& A_{y}(x, y, z, t)=\alpha \operatorname{sech}(\alpha r) \frac{x}{\left(x^{2}+y^{2}\right)} \exp (-i \alpha t / 2), \\
& A_{z}(x, y, z, t)=0 .
\end{aligned}
$$

3. For the vector field of kind (10):

$$
\begin{aligned}
& A_{x}(x, y, z, t)=\alpha \operatorname{sech}(\alpha r) \frac{(z x-r y)}{r\left(x^{2}+y^{2}\right)} \exp (-i \alpha t / 2), \\
& A_{y}(x, y, z, t)=\alpha \operatorname{sech}(\alpha r) \frac{(z y+r x)}{r\left(x^{2}+y^{2}\right)} \exp (-i \alpha t / 2),
\end{aligned}
$$


$A_{z}(x, y, z, t)=-\frac{\alpha \operatorname{sech}(\alpha r)}{r} \exp (-i \alpha t / 2)$,

where $r=\sqrt{x^{2}+y^{2}+z^{2}}$.

The $A_{x}$ component is shown in Fig. 1. when following the expression (15). The solutions are not determined in the origin and they do not admit a limit when $r \rightarrow 0$. We should note, that this is illusive because when $r \rightarrow 0$, then $n_{2} \rightarrow 0$ too as $n_{2}$ depends from $x^{2}+y^{2}$. This leads to linearization of the equation (6) and the problem is divided into two parts:

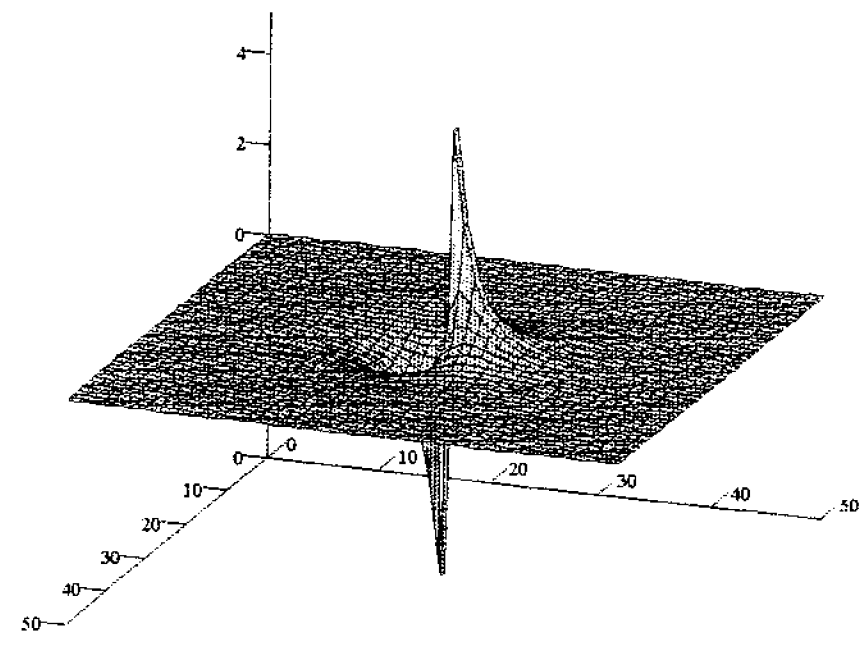

Fig. 1.

i) when $r \ll r_{0}$ we obtain a linear equation from (6).

ii) when $r \approx r_{0}$ we solve the full nonlinear equation (6). This corresponds to a solving of the following mathematical problem:

$$
-i \alpha \frac{\partial \mathbf{B}}{\partial t}+\frac{1}{2} \frac{\partial^{2} \mathbf{B}}{\partial r^{2}}+|\mathbf{B}|^{2} \mathbf{B}=0
$$

when $r \approx r_{0}$ and

$$
-i \alpha \frac{\partial \mathbf{B}}{\partial t}+\frac{1}{2} \frac{\partial^{2} \mathbf{B}}{\partial r^{2}}=0
$$

when $r \ll r_{0}$. We look for smooth conditions of sew up for the function $B$ and its first derivative in ' $r$ ' direction on the boundary. The equation (22) admits the solutions of the kind of:

$$
\begin{aligned}
& B(r, t)=A_{0} \sin (\alpha r) \exp (i \alpha t / 2), \\
& B(r, t)=A_{0} \exp (-\alpha r) \exp (-i \alpha t / 2) .
\end{aligned}
$$

which are finite when $r \rightarrow 0$ and there are possibility for smooth conditions at some fixed $r$ and $\alpha$. So, the full solution is a sum of a solution of linear problem near the origin of the localized waves and a solving of the nonlinear problem when it reaches $r \approx r_{0}$.

\section{DISCUSSION AND SUMMARY}

Recently, experimental evidence of 2D spatial solitons has been reported in [22], [24] using various physical mechanisms of the optical nonlinearity. One of these mechanisms is a diffusion [22] along $z$ (or $x, y$ ). The diffusion effects may be due to the optically excited charge carriers, which become extremely mobile and they travel significant distances before the recombination. This gives a spatial dependence of the nonlinear refractive index upon the coordinate. When both bounding media are nonlinear, then the minimum power which is necessary for the existence of the nonlinear asymmetric guided wave, increases with the diffusion length growth [22]. We should note that the observations of the three dimensional solitons because of large nonlinearity in polymers JEN is also perspective.

In conclusion, we present nonlinear media of suitable symmetry, experimental evidence of three-dimensional solitons in these materials being possible. The proposed reduction of the VNLS allows the find various exact localized soliton solutions and to apply the inverse scattering method to the $3 \mathrm{D}$ case. Following the results of this paper the main application of these optical $3 \mathrm{D}+1$ solitons is in realizing of stable waveguide propagation of laser pulses in dielectric nonlinear media and in semiconductor compounds.
[1] P. L. Kelley, Phys. Rev. Lett. 15, 1005 (1965).

[2] V. I. Karpman, Nonlinear Waves in Dispersive Media (Nauka, Moskow, 1973).

[3] J. V. Moloney, A. C. Newell Nonlinear Optics (AddisonWesley Publ. Comp., 1991).

[4] D. R. Andersen, L. M. Kovachev, J. Opt. Soc. Am. B 19, N3, 376 (2002).

[5] Y. Silberberg, Opt. Lett. 15, 1282 (1990).

[6] D. E. Edmundson, R. H. Enns, Opt. Lett. 18, 1609 (1993).
[7] R. Mc. Leod, K. Wagner, S. Blair, Phys. Rev. A 52, 3254 (1995).

[8] J. M. Soto-Crespo, E. M. Wright, N. N. Akhmediev, Phys. Rev. A 45, 3168 (1992).

[9] D. E. Edmundson, R. H. Enns, Phys. Rev. A 51, 2491 (1995).

[10] G. A. Swartzlander, Jr., C. T. Law, Phys. Rev. Lett. 69, 2503 (1992).

[11] J. Christou, V. Tikhonenko, Yu. S. Kivshar, B. LuterDaves, Opt. Lett. 21, 1649 (1996). 
[12] K. Stalinas, Chaos Solitons Fractals 4, 1783 (1994).

[13] A. V. Mamaev, M. Soffman, A. A. Zozula, Phys. Rev. Lett. 76, 2262 (1996).

[14] V. Tikhonenko, J. Christou, B. Luter-Daves, J. Opt. Soc. Am. B 12, 2046 (1995).

[15] L. Torner, D. V. Petrov, Electron. Lett. 33, 608 (1997).

[16] W. J. Firth, D. V. Skryabin, Phys. Rev. Lett. 77, 2450 (1997).

[17] A. Desyatnikov, A. Maimistov, B. Malomed, Phys. Rev. E 61, 3107 (2000).

[18] B. A. Malomed, L. C. Grasovan, D. Mihalache, Physica
D 161, 187 (2002).

[19] C. T. Law, G. A. Swartzlander, Jr., Chaos Solitons Fractals 4, 1759 (1994).

[20] L. M. Kovachev, S. Donev, R. Rousev, Proc. of the First Symp. of Nonlinear Equations, Sofia, June, 1994.

[21] J. A. Osaheni et al., J. Phys. Chem. 96, 2830 (1992).

[22] P. Varatharajan, J. M. Moloney, A. C. Newell, E. M. Right, J. Opt. Soc. Am. B 10, 146 (1993).

[23] N. Blombergen, Nonlinear Optics (Benjamin, New York, 1965).

[24] J. S. Aitchison et al., Opt. Lett. 15, 471 (1990).

\section{ТРИВИМІРНІ СОЛІТОНИ В СЕРЕДОВИЩАХ ІЗ ПРОСТОРОВОЮ ЗАЛЕЖНІСТЮ НЕЛІНІЙНОГО РЕФРАКТИВНОГО ІНДЕКСУ}

Л. М. Ковачев, Н. І. Каймаканова ${ }^{1}$, Д. Й. Дакова ${ }^{1}$, Л. І. Павлов ${ }^{2}$, Р. А. Русев $^{2}$, С. Г. Донев ${ }^{2}$, Р. Л. Павлов ${ }^{2}$ Інститут електроніки, Болгарсъка академія наук Царіљрадско шосе, 72, 1784, Софія, Болгарія

${ }^{1}$ Пловдівсъкий університет, вул. Царя Асена, 24, 4000, Пловдів, Болгарія

${ }^{2}$ Інститут ядерних досліджень $і$ ядерної енерґї, Царіз'радско шосе, 72, 1784, Софія, Болгарія

Вивчено непараксіяльне векторне узагальнення скалярного нелінійного $3 \mathrm{D}+1$ рівняння Шредингера (НРШ). У сферичному зображенні можна звести це рівняння до звичайного скалярного нелінійного рівняння Шредингера щодо координат $t, r=\sqrt{x^{2}+y^{2}+z^{2}}$. Тому всі періодичні та одиничні НРШ даватимуть $(3 \mathrm{D}+1)$ векторні розв'язки. Таке зведення можливе лише коли просторова залежність нелінійного рефрактивного індексу є типу $n_{2} \cong\left(x^{2}+y^{2}\right) \chi^{(3)} / r_{0}$. Точні аналітичні $(3 \mathrm{D}+1)$-розв'язки вперше отримано в середовищах із просторовою залежністю нелінійного рефрактивного індексу. 